conventional outpatient departments. Outreach clinics were, however, associated with higher NHS costs per patient owing to factors which included lower patient volume, lack of access to diagnostic facilities, and loss of efficiency arising from specialists having to travel between clinics.

A multicentre randomised controlled trial of the effectiveness and costs of video conferencing showed there was no need for consultants to travel to deliver outreach services. Patient satisfaction was improved and ordering of investigations was reduced, although the investigations were mainly the cheaper, routine tests and not the more complex expensive ones. ${ }^{5}$ As with conventional outreach, such virtual outreach was considerably cheaper for patients to access than conventional outpatient services, but was considerably more expensive, per patient, to the NHS. ${ }^{6}$

Current plans for bringing specialties out of hospitals and nearer to people also include the development of new community hospitals to provide diagnostic services, minor elective surgery, outpatient facilities, social services, and a new NHS "life check" to assess patients' lifestyle risks. ${ }^{2}$ Duplication of investigative facilities will be inevitable with such "one stop shops," as will substantial capital costs for buildings and equipment and considerable additional human resource costs. Furthermore, the NHS costs of having general practitioners with special interests covering several local practices can exceed those of hospital outpatient care.

Little is known about the extent of necessary capital investment, nor indeed the impact on hospitals of retrenchment and wasted capital assets. And patients in inner cities, within walking distance of accident and emergency departments, will probably not welcome being obliged to use a general practice amenity that has fewer properly staffed investigative facilities, even if the practice is closer to home.

Evidence of the effectiveness and economic advantage of providing acute primary health care in hospitals is long standing and robust. ${ }^{8}$ Faced with growing financial pressures, hospitals will need to innovate and reconfigure in order to survive. Redeployment of the current vast and complex secondary care asset structure could enable the delivery of a broad range of services that local communities seek and also the potential to franchise space to enable others to do the same. Until now, experience of this kind in the UK has been restricted largely to specific specialties or conditions. However, in countries with relatively fewer primary care physicians (such as the US), such models of hospital based delivery of general community services have been implemented successfully, particularly in areas with deprived populations (for example, Yale-New Haven Hospital Community Service, www.ynhh.org/commsvs.html). Comparative evaluation of the costs and effectiveness of hospital and community based models of service provision will be required in order to assess their relative merits.

The greatest challenge to health policy in England is how best to establish and balance optimum clinic size and range of services while ensuring high quality, efficiency, and cost effectiveness. In making those judgments, leaders of the NHS reforms will do well to draw on lessons learnt from past experience.

Paul Wallace professor of primary care

Ann Bowling professor of health services research

(a.bowling@ucl.ac.uk)

Department of Primary Care and Population Sciences, University College London, London NW3 2PF

Jennifer A Roberts emeritus professor of economics of public health

Department of Public Health and Policy, London School of Hygiene and Tropical Medicine, London WC1E 7HT

Competing interests: $\mathrm{PW}, \mathrm{AB}$, and JAR have been involved in studies of specialist outreach funded by the Department of Health and Health Technology Assessment.

1 Department of Health. Our health, our care, our say: a new direction for com munity services. Norwich: Stationery Office, 2006. (Cmnd 6737.) www.dh.gov.uk/assetRoot/04/12/74/59/04127459.pdf (accessed 19 May 2006).

2 Department of Health. Better services and more choice, on your doorstep. London: Department of Health, 2006.

3 Department of Health. Reforming NHS financial flows: introducing payment by results London: DOH, 2002 www dh ovovuk/assetRoot/04/06/04/76 04060476.pdf (accessed 19 May 2006).

4 Bowling A, Bond M. A national evaluation of specialists' clinics in primary care settings. Br J General Practice 2001;51:264-9.

5allace P. Haines A, Harrison R, Barber J, Thompson A, Jacklin P, et al. Woint teleconsultations (virtual outreach) versus standard out-patient appointments for patients referred by their general practitioner for a specialist opinion: a randomised trial. Lancet 2002;359:1961-8.

6 Jacklin PB, Roberts JA, Wallace P, Haines A, Harrison A, Barber J, et at. Virtual outreach: economic evaluation of joint teleconsultations for patients referred by their general practitioner for a specialist opinion. BMJ 2003;327:84

7 Coast J, Noble S, Horrocks A, Asim O, Peters TJ, Salisbury C. Economic evaluation of a general practitioner with special interests led dermatology service in primary care $B M J$ 2005:331:1444-9.

8 Dale J Lang $\mathrm{H}$ R Dale J, Lang H, Roberts AJ, Green J, Glucksman E. Cost effectiveness of treating primary care patients in accident and emergency: a comparison between general practitioner, senior house officers and registrars. BMJ $1996 ; 312: 1340-4$.

\title{
Tuberculosis and social exclusion
}

\section{Developed countries need new strategies for controlling tuberculosis}

$\mathrm{I}$ $\mathrm{n}$ developed countries most patients with tuberculosis are not infectious, can readily access health services, and complete treatment successfully with minimal supervision from a health worker. As a result they make only limited demands on services and pose little public health risk. By contrast, many socially excluded patients are at risk of delayed presentation, persistent outbreak in London including over 220 drug resistant cases and disproportionately affecting homeless people, prisoners, and problem drug users clearly illustrates the urgent need to strengthen tuberculosis control among socially excluded groups. ${ }^{1}$

Mycobacterium tuberculosis can infect anyone but predominantly affects the poor. Globally, 98\% of deaths from tuberculosis are in the poorest countries. ${ }^{2}$ 
In rich countries tuberculosis mainly occurs in people born abroad and in socially excluded groups. In London, which accounted for over $40 \%$ of all reported cases in the UK in 2004, rates of tuberculosis have more than doubled since $1987^{3}$ and are highest among homeless people, problem drug users, people living with HIV, prisoners, and new immigrants, particularly those from countries experiencing chronic civil conflict. ${ }^{4}$ These risk groups are prevalent in major cities across the developed world. Tuberculosis control is founded on early case detection and complete treatment to minimise transmission and prevent the emergence of drug resistance. But patients from these groups are unlikely to present promptly and take treatment lasting a minimum of six months, and the assumption that they will do so is no longer a basis for effective tuberculosis control.

Recent guidelines from the National Institute for Health and Clinical Excellence (NICE) provide a comprehensive review of the evidence supporting clinical diagnosis and management of tuberculosis and measures for its prevention and control. ${ }^{5}$ They discuss tuberculosis control and future research priorities in some socially excluded groups, specifically homeless people and prisoners. The guidelines do not mention other groups with high rates, such as drug and alcohol misusers. ${ }^{6}$ A recent summary from the Netherlands discusses case detection and control among drug users and homeless people. ${ }^{7}$ Among these groups conventional contact investigation is often not feasible, a low proportion of infected individuals are eligible for preventive treatment, and only a minority may complete the treatment. NICE recommends that active case finding should be carried out among street homeless people (including those using homeless shelters) by chest $\mathrm{x}$ ray screening on an opportunistic or symptomatic basis; the guidelines suggest simple incentives for attending, such as hot drinks and snacks.

People with a history of homelessness and drug and alcohol problems are over-represented in the prison population, and prisons can aggravate transmission of tuberculosis. So the guidelines recommend entry screening for prisoners through a health questionnaire, followed by a chest $\mathrm{x}$ ray for those with signs and symptoms of active disease, but this approach will miss asymptomatic cases. Active case finding among prisoners contributes to tuberculosis control in the community, and chest radiography has been shown to be more cost effective than symptom screening or tuberculin testing and identifies substantially more cases than other screening methods. ${ }^{8}$ Mobile chest radiography targeted at high risk groups in communities where many of them live or meet, such as homeless shelters or services for drug users, is used in the Netherlands and France and is being evaluated in London. ${ }^{9}$

Recommendations to confirm diagnosis and promote treatment continuity include hospital admission for homeless people and those with a clear socioeconomic need, allocation of a named key worker for all patients, and risk assessment to identify patients unlikely to adhere to treatment. Adherence is known to be complicated by the lack of secure accommodation, destitution, and addiction. ${ }^{10}$ NICE recommends directly observed therapy (DOT) for homeless people and those who are likely to be poorly adherent, recognising that DOT alone is unlikely to lead to improved outcomes unless provided in conjunction with a package of supportive care tailored to patients' needs. ${ }^{11}$ The guidelines emphasise the importance of stable accommodation, financial support to cover transport and prescription costs, and treatment arrangements that are practicable for the patient. Many observational studies point to the effectiveness of directly observed therapy, but the evidence from randomised controlled trials is conflicting. ${ }^{12}$

If the major determinants of a disease are social, so must be the remedies. ${ }^{13}$ Tuberculosis cannot be controlled unless the disease is tackled effectively among socially excluded groups. This demands coordinated action beyond established control strategies that will require significant and sustained investment.

\section{Alistair Story TB nurse and scientist}

(Alistair.Story@hpa.org.uk)

Tuberculosis Section, Respiratory Disease Department, Centre for Infections, Health Protection Agency, London NW9 5EQ

\section{Rob van Hest consultant TB physician}

Tuberculosis Section, Department of Infectious Disease Control, Rotterdam Public Health Service, Rotterdam, 3011 EN, Netherlands

Andrew Hayward senior lecturer in infectious diseases

University College London, Centre for Infectious Disease Epidemiology, London NW3 2PF

Competing interests: $\mathrm{AH}$ was Faculty of Public Health representative on the NICE guideline development group.

Isoniazid mono-resistant tuberculosis in north London-update. $C D R$ Weekly 2006:16:3.

2 Stop Tuberculosis Initiative. Report by the Director-General. 2000. www.who.int/gb/ebwha/pdf_files/WHA53/ea5.pdf (accessed $11 \mathrm{Apr}$ 2006).

3 Annual report on tuberculosis cases reported in England, Wales and Northern Ireland in 2003. London: Health Protection Agency Centre for Infections, 2005 .

4 Story A, Roberts W, Hayward A, for the London Tuberculosis Nurses Network. Tuberculosis in London: results of the 2003 TB case load profile. Int J Tuberc Lung Dis 2004;8:S197.

5 National Institute for Health and Clinical Excellence. Tuberculosis. Clinical diagnosis and management of tuberculosis, and measures for its prevention and control. London: NICE, March 2006. www.nice.org.uk/ page.aspx?o = 296657 (accessed 11 Apr 2006).

6 Golub JE, Mohan CI, Comstock GW, Chaisson RE. Active case finding of tuberculosis: historical perspective and future prospects. Int J Tuberc Lung Dis 2005;9:1183-203.

7 De Vries G, Van Hest R. From contact investigation to tuberculosis screening of drug addicts and homeless persons in Rotterdam. Eur J Public Health 2006;16:133-6.

8 Jones TF, Schaffner W. Miniature chest radiograph screening for tuberculosis in jails: a cost-effectiveness analysis. Am J Respir Crit Care Med 2001;164:77-81

9 KNCV Tuberculosis Foundation. Index Tuberculosis 2001-2002. The Hague: KNCV Tuberculosis Foundation, 2005.

10 Sumartojo E. When tuberculosis treatment fails: a social behavioural account of patient adherence. Am Rev Respir Dis 1993;147:1311-20.

1 Volmink J, Matchaba P, Garner P. Directly observed therapy and treatment adherence. Lancet 2000;355:1345-50.

12 Volmink J, Garner P. Directly observed therapy for treating tuberculosis. Cochrane Database Syst Rev 2003;(1):CD003343.

13 Marmot M. Social determinants of health inequalities. Lancet 2005;365:1099-1104. 